\title{
Recognizing and Addressing the Seismic Shift in Child Psychosocial and Emotional Wellbeing: Technological Implications and Recommendations for the Current and Future Social Realities of Twenty-First Century Children
}

\author{
Celeste Duff ${ }^{1} \&$ Jillian Roberts ${ }^{2}$ \\ ${ }^{1}$ Celeste Duff, University of Warwick, United Kingdom. \\ 2 Jillian Roberts, University of Victoria, Canada. \\ Correspondence: Celeste Duff, Celeste Duff, University of Warwick, United Kingdom.
}

Received: June 2, 2016

Accepted: June 14, 2016

Available online: June 30, 2016

doi:10.11114/ijsss.v4i8.1706

URL: http://dx.doi.org/10.11114/ijsss.v4i8.1706

\begin{abstract}
There are new realities of the modern age that can directly and indirectly implicate the current and future psychosocial development and emotional wellbeing of children. The following discussion in this article emanates from the common position of both authors who recognize a seismic shift in the lives of children has occurred. Both authors hold the position that the social realities of children have changed and continue to change. At the core of this shift lies an advance in technology; a technological advance so fluid, which has effectively rapidly disseminated into society and transformed children's social realities. In this article, the realities of the psychological and emotional wellbeing concerns of children will be discussed, in addition to the implications of the new social realities for children, with a specific focus on technological advances, educational and parental implications. Finally, recommendations will be presented for addressing the seismic shift that has occurred in the social realities of children. The objective of this article is to therefore recognize the seismic shift and to offer recommendations to facilitate positive psychosocial and educational developmental pathways for the current and future social realities of twenty-first century children.
\end{abstract}

\section{Introduction}

The objective of this article is to recognize the seismic shift that has occurred in the social realities of children; a seismic shift in technological advances, however also increasing psychosocial and emotional wellbeing concerns. This article will discuss the new social realities of children, specifically focusing on the implications for which technological devices and technological advances can have on children's psychological health and development. The statistics surrounding the current and future concerns of children's psychological and emotional wellbeing concerns will be presented. Following this, the implications for which the seismic shift in technological advances and increasing psychosocial and emotional wellbeing concerns can create for schools, teachers, and parents will be discussed. Finally, recommendations will be offered for schools, teachers, and parents to support the psychosocial and emotional wellbeing of children amidst the seismic shift of technological advances and increasing psychosocial and emotional wellbeing concerns.

The technological advances referred to in this article are identified as devices such as computers, smartphones and further mobile devices, which provide the accessibility for interactive and online communication platforms such as E-mail, Facebook and Instagram. The terms child, children, and youth are used interchangeably within this article; this refers to persons who have yet to reach the age and conditions associated with adulthood.

\section{The new social realities of twenty-first century children}

Children are now growing up within a reality that is heavily induced and reliant on technological advances. Amidst such technological advances, there also lies a reality of climate change, ongoing civil tension and unrest and ongoing racial divides. It is accepted that children are growing up and entering into realities of rapid advancements, however also rapid ecological and humane decline. Such realities have already proved to implicate the psychosocial development and wellbeing of children; a reality induced with polarized variables can create implications for the current and future 
psychological wellbeing of children.

Due to the rapid growth in technology, and thus a shift in the prominence of technology in children's lives, there are commentators who warn children's "cognitive, emotional, and social development is under threat" (Plowman, McPake and Stephen, 2010, P.63). In what follows, commentators and research that propose technological devices and online communication can negatively impact the psychosocial development and wellbeing of children will be presented.

A study conducted by Pea, Nass, Meheula, et al (2012) found that negative social wellbeing was positively associated with technological devices central to interpersonal communication such as phone and online communication. Additionally, multitasking with multiple technological devices was also associated with negative social indicators. This study however concluded that face-to-face communication indicated a strong association to positive social wellbeing.

There are commentators who hold the position that online communication can result in social isolation due to excessive time spent on accessing online communicative platforms alone. Said participation of online communicative platforms accessed through technological devices is considered a socially impoverished medium (Stoll, 1995; Turkle, 1996). Within this vein, Kraut, et al. (1998) report that a greater use of online accessibility and communication is associated with minor, however statistically significant declines in social participation and increases in loneliness. Greater use of online accessibility and communication can also be associated with increases in depression; Kraut, et al. (1998) thus deem, online accessibility and communication can adversely implicate social participation and psychological wellbeing. Similarly, research has found a correlation of dysthymia, that is chronic depression, to excessive attachments of online platforms. A study conducted by Lu et al. (2011) found depression to be associated with online and social communication dependency. While, Rosen, Whaling, Rab, Carrier, and Cheever (2012, P.1243) report on a new psychological disorder referred to as an 'iDisorder' which effectively defines the negative relationship between technology usage and psychological health.

Equally, the dependency of online and social communication can also be known as Internet addiction, compulsive Internet use, compulsive computer use, and pathological Internet use (Liu \& Potenza, 2007; Mitchell, 2000). These terms refer to the compulsive and excessive use of the technological devices and the negative psychological, psychosocial, and emotional wellbeing symptoms when deprived of said technological devices (Mitchell, 2000). Young and Rodgers (1998) who coined the term, 'Internet addiction disorder' define this disorder as an impulse-control disorder that does not involve intoxication, however the diagnostic criteria for 'Internet addiction' are similar to those for chemical substance dependence (as cited in Lu et al, 2011). To this end, clinicians and researchers associate compulsive and excessive use of technological devices and online communication is associated to substance and behavior addiction (Mitchell, 2000). Said association is reinforced by the commonality of the negative impact on psychological adjustment.

A contemporary and prevalent platform for online communication, Facebook, can be considered an invaluable resource for achieving basic human needs of social participation. However Kross et al (2013) take the position that there is evidence to suggest that may undermine wellbeing, rather than enhance it. A study lead by Kross et al (2013) revealed significant findings of correlations and implications among wellbeing and the contemporary online platform, Facebook. This study found that the greater the participants accessed and interacted with Facebook, the greater their decline of cognitive and emotional wellbeing. These findings indicated the motivations for Facebook use derived from feelings of boredom, loneliness and distress (Kross et al, 2013). Thus, the greater feelings of boredom, loneliness and distress, initiated the greater access and interaction with Facebook, which thus contributed to a greater decline in wellbeing. Within this vein, the American Pediatric Association's Council on Communications and Media reported that 'Facebook depression' was a potential problem for children and youth (O'Keeffe \& Clarke-Pearson, 2011). Additionally, there are commentators who argue that narcissism is exacerbated, and even encouraged, by online platforms (Bergman et al., 2011). Findings indicate that the greater amount of time spent on Facebook and a higher frequency of checking Facebook predicted higher narcissism scores (Mehdizadeh, 2010; Ryan \& Xenos, 2011).

It is however important to recognize the correlations and implications between Facebook and wellbeing can be influenced by a multitude of factors such as the quantity and quality of social online networks, the context of online participation, depressive symptomology, and self-esteem. Based on these findings, Kross et al (2013) hold the view that direct social interactions achieve positive human needs of social participation, whereas Facebook may constitute a form of online social participation that predicts impoverished wellbeing.

A study conducted by Howard-Jones (2011) provided evidence to suggest that children are more susceptible than adults to environmental influences. Howard-Jones' (2011) study revealed that children displayed an increase in aggressive behavior, interference with psychosocial wellbeing, interference with concentration, and disrupted sleep patterns as a result of engaging in excessive online interactive platforms (as cited in Plowman and McPake, 2013, P.6). Seeing as children are developing socially, emotionally, physically; and aligned with this study, neurologically; the impact of online interactive platforms can provide significant concerns for their wellbeing and development. 
Within the position of technological devices and online communication negatively impacting the psychosocial development and wellbeing of children, it is clear there can be multiple subsequent risks. The most common risk can be identified as online bullying. This form of bulling, also known as Cyber bullying, involves the deliberate online communication of false, distressing, or hostile information towards another (O'Keeffe and Clarke-Pearson, 2011). Seeing as Cyber bullying in children is identified as a common risk, this risk can be considered as a prominent precursor for profound psychosocial outcomes including depression, anxiety, severe isolation, and suicide (Hinduja and Patchin, 2010).

Children inherently encompass a limited capacity to self regulate and are therefore more susceptible to peer pressure and negative experimentation of online spaces and communication. Research indicates that there is a strong presence of online expressions of offline behaviors, including bullying, clique-forming, and sexual experimentation (Lenhart, 2009). Additional risks which children and youth may also be susceptible to, include, concurrent sleep deprivation, and online communication and Internet addiction (Christakis and Moreno, 2009).

Conversely, there are however commentators who find positive implications as a result of children accessing and participating in the technological advancements and the interactive online communicative platforms. In what follows, commentators and research that propose technological devices and online communication can positively contribute to the psychosocial development and wellbeing of children will be presented.

Plowman and McPake (2013) propose that children who have grown up in the era of technological advances and the prominent presence and accessibility of technological devices have a natural bond to technology, and thus accessing and participating in online interactions is considered a comfortable method of communication. Prensky (2001) identifies those children who have grown up with technological advancements and effectively developed an attachment to technological devices and the online world, as 'digital natives'. Within Plowman and McPake (2013) and Prensky's (2001) view, technology can be considered a positive tool in stimulating learning experiences with the support of adults in guiding children's learning experiences.

Research has reveled that children and youth are using online spaces to connect with others to discuss and address developmental issues. The main objective for children and youth accessing technological devices, and participating in online interaction, can be understood as solely a method of communication and contact (Reich, Subrahmanyam, and Espinoza, 2012). Furthermore, research has also indicated that multiple forms of online communication for children and youth have revealed positive development of skills and abilities. These include, the development of social connections and relationship building, dialogue and correspondence, and also procedural skills (Ito, Horst, and Brittani, 2008). More specifically, in regards to cell phone use, research indicates children who spend more time talking on the phone prove to be less proficient at word decoding, whereas children who spend more time sending text messages hold a greater level of reading comprehension (Hofferth and Moon 2012). Within this vein, further positive benefits for children having the opportunity to access online spaces can involve the development of enhanced learning and more specifically, greater benefits connected to self-identity, community, and the world. Online spaces, within applicable contexts, can enable greater community engagement, creativity, self-development, and enhance the collaboration of ideas for learning and educational development (Ito, Horst, and Brittani, 2008 and Boyd, 2007).

Some commentators also argue that the accessibility to technological devices and communicative platforms for children and youth can lead to increasingly positive social connections by freeing people from the constraints of geography or isolation brought on by stigma, illness, or schedule (Katz \& Aspden, 1997; Rheingold, 1993). To this end, technological devices and communicative platforms for children and youth can be seen to encourage a collective and reciprocal connectedness among children and youth.

Research has revealed that social networking sites such as the contemporary and prevalent platform for online communication, Facebook, are influential in supporting children and youth to satisfy enduring human psychosocial needs for permanent relations in a geographically mobile world (Manago, Taylor \& Greenfield, 2012). Furthermore, research has indicated that larger networks and larger estimated audiences predicted higher levels of life satisfaction and perceived social support on Facebook (Manago, Taylor \& Greenfield, 2012). Similarly, Steinfield, Ellison, \& Lampe (2008) propose that social networking sites facilitate bridging social connections and those with low self-esteem reportedly experience greater social and emotional gains in their social connections. To this end, it is clear some commentators and research propose that communicative platforms can be considered useful tools for procuring social support and subsequently, positively influencing psychosocial needs.

\section{Psychological and emotional wellbeing concerns of children}

There are claims of an urgency and concern for the current and future psychological and emotional wellbeing of children (Duff, 2015). There are commentators who hold the position that psychosocial development, emotional wellbeing concerns, and learning dysfunctions among children are increasing on a global scale. An alarming escalation in the number of children who are unable to fully function due to increasing psychosocial and emotional wellbeing 
implications (Melillo, 2009). This concern can be perceived as a new phenomenon, and a critical health issue of our time. The World Health Organization (WHO) also holds a position of urgency related to increasing emotional well-being concerns. The WHO predicts "rates of migration and speed of globalization and urbanization will affect psychiatric vulnerability" (MHF, 2013). Melillo and the WHO hold similar positions; they argue as a result of progressive yet destabilizing societal and economic changes, the psychosocial and emotional well being of children can be affected. Melillo and the WHO perceive and predict the resilience of children's emotional wellbeing will likely be tested and become strained. The WHO's position of urgency and criticality is further solidified as the WHO identifies mental health services in the United Kingdom to have the highest funding accountability in comparison to all other health areas including heart disease and cancer (MHF, 2013). While, in Canada, metal health concerns among children is also increasing; Canada's youth suicide rate is the third highest in the industrialized world, with one out of five children requiring mental health services and support (CMHA, 2016). In the United States, thirteen to twenty percent of children, that is, one in five children, experience a mental disorder in a given year. The mental health services for children in the United States therefore have an estimated \$247 yearly expenditure (CDC, 2015). Forecasts from the World Health Organization warn that by 2020 neuropsychiatric disorders in children will increase by fifty percent, thus neuropsychiatric disorders in children will be one of the five significant causes of death (Palmer, 2006).

\section{Implications for Schools, Teachers and Parents}

It can be understood that our economies, and thus our social realities and cultures have rapidly evolved; it is from this seismic shift and rapid technological advances that has triggered complex concerns (Palmer, 2006). The seismic shift that has occurred in the social realities of children not only create implications for children and youth, this shift effectively also creates implications for all those connected to children. Specifically, individuals who are positioned to positively influence the current and future psychosocial development of children and youth are experiencing a misalignment and disconnect in meeting said needs. It is evident children now have different needs, however teachers and parents are often not aligned in guiding and offering children what they require; education may hold lesser reference, and parental guidance may also hold lesser applicability and validity within the context of twenty-first century learning and development (Duff, 2015).

This seismic shift can be seen to have effectively triggered a 'digital generation gap'. The key and critical individuals present within a child's life, that is, parents/carers and teachers, increasingly have limited reference points to support the psychosocial development, educational journeys, and wellbeing of children. The individuals positioned to positively influence the current and future psychosocial development of children and youth did not grow up within the current social realities, therefore providing the necessary frameworks, paradigms, and discourses that are specifically aligned with the digital generation and the twenty-first century learning can be problematic.

In current educational climates, teachers are increasingly unable to address the demands emanating from educating the digital generation. Teachers are often implicated into responsibilities aligned with that of psychologists and social workers; within a climate of rapid social reality change for children and youth, teachers are often unable to align educational paradigms and pedagogies to meet the needs of this digital generation and twenty-first century learning (Buckingham and Willet, 2013). As a result of this misalignment, children and youth are exhibiting concerns connected to psychosocial development, emotional wellbeing, socio-cultural tensions, as well as increased learning dysfunctions. The multiple concerns experienced by children and youth in addition to demands placed on teachers has developed into a vicious cycle (Jennings and Greenberg, 2009). UNICEF hones into the responsibility education holds for children; Article 28 of the Convention On the Rights of the Child, places a high value on the responsibility of education. Article 28 states "young people should be encouraged to reach the highest level of education of which they are capable" (UNCRC, 1989). While, Article 29 expresses education as holding the responsibility in developing "each child's personality, talents and abilities to the fullest. [Education] should encourage children to respect others, human rights and their own and other cultures" (UNCRC, 1989). Said articles from the Convention On the Rights of the Child indicate that there is a responsibility education holds in providing educational provisions that will encourage children to develop the skills and abilities to navigate and flourish within their societies. However, within the current educational climate and the complexities associated with the current digital generation, and twenty-first century education, industrialized societies are becoming increasingly misaligned to provide the relevant and necessary educational provisions (Duff, 2015).

Seeing as parents also often have limited reference points in supporting the psychosocial development, educational journeys, and wellbeing of children as a result of the digital generation, this can impact child-parent relationships and thus effectively hinder the psychosocial development and emotional wellbeing of children. Parents are often not equipped with the technical abilities or time required to keep up to date with their children in the ever-evolving, innovative, online landscape (Palfrey, Glasser, and Boyd, 2010). Additionally, with parents having not grown up in a digital generation, parents often lack an awareness of the scope, objectives and implications the online world. 
Subsequently, this generation gap and disconnect can create tensions and effectively hinder the psychosocial development, educational journeys, and wellbeing of children and youth; and thus subsequently manifest inharmonious child, parent, and family development and relations (O'Keeffe and Clarke-Pearson, 2011).

\section{Recommendations for Addressing the Seismic Shift}

It is important for individuals who are positioned to positively influence the psychosocial development and emotional wellbeing of children to recognize this seismic shift and for action to be taken. It is evident there are new social realities for children, and those realities can negatively impact their psychosocial development, however also enhance multiple developmental skills and abilities. It is also evident that mental health concerns among children are increasing, while the misalignment and disconnect among the digital generation and their influential figures remain.

\subsection{Recommendations for schools and teachers}

A shift is required in the approach to educational pedagogies and paradigms while recognizing and addressing the digital generation's psychosocial and emotional wellbeing development. In what follows, recommendations will be provided for schools and teachers.

\subsection{Encourage student voice and autonomy.}

When students have the opportunity to develop a sense of self-efficacy and consultation within their school environments and learning contexts, this connection and involvement can have multiple benefits for their psychosocial and emotional wellbeing. If schools were to provide online spaces to be used as communicative platforms where children have the opportunity to collectively collaborate through expressing their voice and autonomy, this would be accepting and encouraging the online world, while facilitating communicative, collaborative and create skills.

Encouraging student voice and autonomy entails authentic involvement and consultation of students within their schools environments and learning contexts. For example, in schools, if online learning resources were accessible 24 hours a day, 7 days a week, children would have the opportunity to manage their time and carry out school assignments in a manner that best supports their learning. If schools were to provide opportunities and skills development for innovation and entrepreneurship, this would enhance greater skill and self-development, thus enabling children to flourish and navigate within their digital generation. The digital generation is considered to encompass concentrated abilities of inquisitiveness, autonomy and self-direction; this generation emanates high analytical, skeptical, and critical thinking skills and abilities (Buckingham and Willett, 2013). It is therefore important for educational pedagogies and paradigms to align, and cater towards developing these skills and abilities. Successfully applied, encouraging student voice and autonomy can provide positive benefits for student's psychosocial and emotional wellbeing by building that vital and protective sense of school connection, increasing responsibility for their own learning and development through self-reflection and inquiry, developing their self identity and self esteem, and enhancing their interpersonal skills.

\subsection{Encourage supportive school and classroom climates.}

The climate and ethos of a school and classroom can create implications for student's psychosocial and emotional wellbeing. The underlying tone and attitudes, in addition to the values and beliefs present within schools and classrooms have the capacity to shape students learning experiences and thus development. The underlying tone which permeates every aspect of school and classroom life and has been shown to be one of the key determinants of wellbeing and mental health in schools; it indeed shapes everything significant to the success of a school (Weare, 2015). If schools and teachers are able to create activities, online spaces or interactive social opportunities for students to communicate concerns, ideas and contributions associated to encouraging supportive school and classroom climates, this will positively encourage the overall ethos of school environments. For example, rather than asking students to consider what profession they would like to be in when they grow up, teachers could ask students to consider what problem they feel passionate about and want to solve; activities, online spaces and interactive social opportunities can be centered around this concept. We cannot ignore that children futures lay within rapid advances, however also mounting concerns from which our current societal infrastructure has yet to, and unable to contended with (Duff, 2015). Such mounting concerns of climate change, ongoing civil tension and unrest, ongoing racial divides, and technological complexities are the current and future reality of our children. A key determinant in encouraging supportive school and classroom climates is the familiarity of routines in supporting a sense of security, and environments where students can communicate, while feeling understood, and empowered. A supportive school and classroom climate has the capacity to positively influence the interconnectedness of a school; successfully encouraged, students psychosocial and emotional wellbeing has the ability to be developed by greater levels of acceptance, respect, and reciprocal connections to schools and classroom environments. Weare (2015, P.5) reaffirms, connected schools and classrooms have low levels of conflict and disruptive behavior; smooth transitions, appropriate expressions of emotion, respectful communication and problem solving, a sense of warmth, supportiveness and responsiveness to students needs. 


\subsection{Identify and Intervene Early.}

Early identification and intervention of psychosocial and emotional wellbeing concerns can directly support students development, and thus learning experience at school. Identifications and interventions of psychosocial and emotional wellbeing concerns which are targeted within preschool and early elementary stages can prevent minor mental health problems from escalating and becoming of clinical significance and can also significantly reduce the need for further interventions or sanctions at a later stage (Weare (2015, P.6). Early identification and interventions can include regular meetings with parents to monitor student concerns, referrals to school councilors, referrals to psychologists, and referrals to child safeguarding and social work teams.

It is also important to note that although identifications and interventions for preschool and early elementary and support students' psychosocial and emotional wellbeing, students who are involved in significant changes, shifts and transitions can also benefit from early identifications and interventions. Said students who are experiencing changes, shifts, and transitions within their lives can be considered vulnerable and therefore schools and teachers need to be sensitive towards their circumstances and support they may require. For example students who are changing schools, students new to a school and or location, and students experiencing family and or living changes. Particularly in adolescence, the hormonal shifts for students can create profound challenges in psychosocial and emotional wellbeing development. If schools and teachers adopt methods of awareness in recognizing psychosocial and emotional wellbeing concerns, and have protocols in place to identify and intervene this can also support and prevent further complications for students. If schools and teachers encompass comprehensive understandings of adolescence psychosocial and emotional wellbeing development, and are equipped with appropriate protocols to identify concerns and respond to concerns, this can significantly support student's current and future psychosocial and emotional wellbeing development.

\subsection{Teach social and Emotional Skills}

Positive and supportive school environments are created by the social and emotional skills of those who work and learn there. Social and emotional skills demonstrably support students to navigate the challenges, and said skills can provide resiliency and preventative measures from psychosocial and emotional wellbeing risks. Key social and emotional skills can include self-concept, self-awareness, emotional literacy, problem solving, resilience, focus, interpersonal skills, and empathy. Social and emotional skills hold the capacity to positively support students learning processes and school experiences.

Schools, by default, hold the position of having a significant role in explicitly teaching the skills and accompanying attitudes and values that lie at the heart of social and emotional wellbeing (Weare, 2015, P.6). Schools need to be creative, proactive and practice in the methods by which social and emotional skills are taught. Social and emotional skills can be taught through a multitude of methods; interactive games, team activities, face-to-face and online communicative platforms, student led symposiums, and extracurricular events. It is important that while various methods can be implemented in order to teach social and emotional skills, the approach and discourse applied towards social and emotional wellbeing is that of a positive, universal focus. A positive, universal focus emphasizes on the capacity and empowerment from which social and emotional skills can activate. If there is a focus on the lack of social and emotional skills, and the detrimental effects this can have upon the psychosocial and emotional development on students, this may manifest negative connotations, expose the vulnerability in students, or induce stigmas. A positive, universal approach in teaching social and emotional skills can further reinforce the interconnectedness and supportive school climate.

\subsection{Recommendations for parents}

Parents and carers are key influencers of their children's psychosocial and emotional wellbeing development. Therefore, there is a significant accountability for parents and carers to ensure their children practice a balanced approach and navigate their technological discourses appropriately. In what follows, recommendations will be provided for parents and carers in supporting the psychosocial and emotional wellbeing of children.

\subsection{Maintain involvement in school life}

If parents and carers develop close ties with schools and teachers, psychosocial and emotional wellbeing developmental concerns are more likely to be recognized and addressed. When parents and families work together with schools and teachers, this can significantly support the recommendations for schools as per presented above, and also positively reinforce parental guidance, attitudes, and approaches. As mentioned, schools are in a position to influence children's wellbeing, thus this responsibility also holds ties to parental and family life. Parents can informally connect with schools and teachers, or more formally through planned meetings, parental courses, or designated family support workers. Furthermore, at home, parents and carers can access school websites and stay connected with school events, activities, and important dates. Staying involved in children's school life, not only connects parents to the school; this involvement emphasizes the value, recognition and importance placed on children's development. Consistent parental connection to 
children's school life can enrich their psychosocial and emotional wellbeing and also prevent concerns from arising or increasing.

Schools and teachers hold the position and the responsibility to ensure students are learning and developing to highest capability; recognizing the psychosocial and emotional wellbeing of students is encompassed within this responsibility and is a significant contributor to students overall learning process, experience and success. When partnerships are developed among schools, teachers, and parents/carers, this creates significant opportunities for positive benefits within both family and school contexts.

\subsection{Maintain child-parent relationships}

Although generation gaps, and specifically the digital generation, can cause a separateness and disconnectedness in parental and family relationships, child-parent relationships however remain a key influential factor in the psychosocial and emotional wellbeing of children. Technological advances cannot replace human connectivity or relationships or replace the value gained in those human interactive experiences. It is however important to recognize that, appropriately used, technological devices and technological advances can serve as a catalyst for child-parent social interaction and development associated with children's academic, psychosocial and emotional wellbeing (Young 2001).

In order to maintain child-parent relationships, it is essential parents receive the new social realities by which their children are developing within by approaching the digital generation objectively. There needs to be an acceptance of technological advancements and thus an acceptance and appreciation of the digital generation. This technological, and online world seismic shift will continue to disseminate despite the misalignment and disconnect from previous generations. If parents, and schools, encourage technological change and advancement and incorporate many of the positive implications into daily life, children will have the opportunity to develop further skills in successfully navigating the social realities in which they live in.

A key component in supporting the psychosocial and emotional wellbeing of children through maintaining child-parent relationships is for parents/carers to recognize technological devices and technological advancements as not solely as new ways to interact, however as new tools for children to learn, create, and explore. It is critical, however, to find a balance, knowing how to align the elements of healthy childhood with the unique capabilities offered by technology; this is where maintaining child-parent relationship holds paramountcy (Van Scoter, Ellis, and Railsback, 2001).

Technological devices can be used as tool for parents/carers to access multiple academic related activities and games, which can engage both the parent and the child. These learning experiences effectively maintain the parent-child relationship in that bonding, greater interaction, and the recognition and value for the digital generation is upheld. All encompassing the psychosocial and emotional wellbeing benefits of maintaining child-parent relationships though technological related games and activities, children's language development, motor development, social development and cognitive development.

Language and literacy development are key strengths of technology for children. Technological, interactive learning experiences can encourage greater, more complex language and literacy development. Technological learning experiences can also allow for motor development. The agility, speed, fine-motor control, and hand-eye coordination and physical responsive actions while engaging in the technological experience can offer opportunities for motor development. Appropriately carried out, technological learning experiences can serve as positive social experiences that develop social interaction and social connectivity for both the parent and child. Finally, cognitive development in children can be promoted. Technological learning experiences promote greater gains in verbal and nonverbal skills, problem solving, and abstraction and conceptual skills (Young, 2001).

\subsection{Nurture children's self-development}

Children and youth are essentially actors within their online worlds; and it can be argued that as a result the digital generation encompasses high levels of self esteem, efficacy and self worth (Buckingham and Willett, 2013). It is however the responsibility of parents to ensure a balance of online and offline realities are established to ensure children's high self esteem, efficacy and self worth is maintained in both online and offline realities. If parents can implement face-face activities and family events this can support in creating a balance and clear distinction between their children's online and offline realities. Ensuring children are regularly exposed to daily realities and offline personal communications and connections is key, as unrealistic perceptions, and effectively inaccurate emotional and psychosocial realities can develop due to over emersion in the online world. Further strategies for fostering self-esteem can include providing opportunities for greater responsibility, accountability, opportunities to make autonomous decisions and autonomous problem solving, and providing consistent positive reinforcement. While nurturing children's self-esteem it is important to respect differences. Every child encompasses their own unique preferences, talents and abilities and it is important parent honor and respect children's individuality and achievements. Similarly to positive 
reinforcement, respecting and honoring children for who they are can contribute in developing their self-esteem.

Encouraging self-management in children can also indirectly enhance children's psychosocial and emotional wellbeing. A child who posses self-management skills has the ability to set and work towards goals, manage and balance daily activities. Specifically aligned to their psychosocial and emotional wellbeing, through developing self-management skills, children can recognize, reflect, assess and positively act on their actions behavior. In relation to technological devices, parents can encourage and instill self-management skills through encouraging appropriate time-management for online use and responsibilities surrounding the context in which online connectivity and communication is carried out. The American Academy of Pediatrics recommends screen time of technological devices at a maximum of one to two hours per day for young children (Young, 2001).

Self-awareness is another facet connected to self-management. Providing opportunities for children to express their feelings, discuss situations and problems, and reflect on their feelings, actions and behaviors will enable children to mange themselves. Gaining the ability to manage and regulate behavior can be very empowering for children. When children develop a greater connection and understanding of themselves, they will have a greater ability to develop a sense of autonomy, responsibility for themselves and their actions. In holding self-management skills, children can develop greater relationships with themselves and others, and lead far more conducive and positive home and school lives.

\section{Conclusion}

It is clear the social realities of children have changed, and that at the core of this change is the presence of technological advancements. The accessibility children and youth have to technological devices and thus the online world is a shift that some commentators perceive holds negative implications to the psychosocial development and wellbeing of children. There are however, conversely, some commentators who perceive this accessibility to technological devices and the online world as a positive shift. Within this view, the online world can be used as a platform for children and youth to connect and communicate developmental issues, educationally collaborate, develop self-identities, and enhance language, interactional and creative skills and abilities.

A review of the literature confirms that there are growing concerns surrounding the psychosocial and emotional wellbeing of children. Specifically, statistics in the United Kingdom, Canada and the United States indicate there are increasing mental health concerns among children. There are also new social realities, with technological advances at the core, for which children and youth are presently navigating. Amidst the new social realities of children, an educational and parental disconnect and misalignment can be found.

The accountability for which educational and parental influences hold for children, plays a highly influential and crucial role is children's psychosocial development and emotional wellbeing. There is a correlation between childhood experiences and the impact those experiences have on the current and future psychosocial development and emotional wellbeing of children. As discussed, technological advancements and the online world is now a social reality for children and youth; the prominent online world therefore has the capacity for positive and negative implications.

All individuals who are positioned to positively influence the psychosocial development and emotional wellbeing of children hold a responsibility in recognizing and addressing the changes and implications of the new social realities. The seismic shift of technological advances, the digital generation and the increasing concerns of child psychological mental health are important, critical concerns of our time; these are concerns for all who are connected to children. Leaders in psychology and education are uniquely positioned to influence and support the psychosocial development and emotional wellbeing of children; with the complexities of a seismic shift and the prominence of increasing child mental health concerns, the accountability for leaders in this field has peaked. In order for children and youth to have the opportunity to positively navigate and flourish within their digital generation, there is accountability for which leaders in psychology and education hold in facilitating progressive yet conducive, educational and developmental pathways aligned with the twenty-first century.

\section{References}

Bergman, S., Fearrington, M., Davenport, S., Jacqueline, Z., \& Bergman, J. (2011). Millennials, narcissism, and social networking: What narcissists do on social networking sites and why. Personality and Individual Differences, 50, 706-711. http://dx.doi.org/10.1016/j.paid.2010.12.022

Boyd, D. (2007). Why youth (Heart) social network sites: the role of networked publics in teenage social life. In: Buckingham, D., ed. MacArthur Foundation Series on Digital Learning: Youth, Identity, and Digital Media. Cambridge, MA: MIT Press.

Buckingham, D., \& Willet, R. (2013). Digital Generations: Children, Young People, and the New Media. Oxon: Routledge Publishing. 
Canadian Mental Health Association (CMHA). (2016). http://www.cmha.ca/ (Accessed May 30 ${ }^{\text {th }}$, 2016).

Centre for Disease control and prevention (CDC) Children's Mental Health - New Report November 2015. US department of Health and Human Services.

Christakis, D., \& Moreno, M. (2009). Trapped in the net: will Internet addiction become a 21 stcentury epidemic? Archives of Pediatrics and Adolescent Medicine, 163, 959-960.

Duff, C. (2015). Children's subjective wellbeing: current and future implications within society, policy, and education (Unpublished manuscript). The University of Warwick, United Kingdom.

Hinduja, S., \& Patchin, J. (2010). Cyber-bullying. Delhi Psychiatry Journal, 13, 131-133. http://dx.doi.org/10.1111/j.1746-1561.2010.00548.x

Hofferth, S., \& Moon, J. (2012). Cell phone use and child and adolescent reading proficiency. Psychology of Popular Media Culture, 1(2), 108-122. http://dx.doi.org/10.1037/a0027880

Howard-Jones, P. (2011). The impact of digital technologies on human wellbeing: Evidence from the sciences of mind and brain. Oxford, Nominet Trust.

Ito, M., Horst, H., \& Brittani, M. (2008). Living and Learning With New Media: Summary of Findings From the Digital Youth Project. The MacArthur Foundation Reports on Digital Media and Learning. Cambridge, MA: MIT Press.

Jennings, P., \& Greenberg, M. (2009). The Prosocial Classroom: Teacher Social and Emotional Competence in Relation to Student and Classroom Outcomes. Review of Educational Research, 79, 491-525. http://dx.doi.org/10.3102/0034654308325693

Katz, J. E., \& Aspden, P. (1997). A nation of strangers? Communications of the ACM, 40(12), 81-86

Kraut, R., Patterson, M., Lundmark, V., Kiesler S., Mukophadhaya, T., \& Scherlies, W. (1998). Internet paradox: A social technology that reduces social involvement and psychological well-being. American Psychologist, 53, 1017-1031. http://dx.doi.org/10.1037/0003-066X.53.9.1017

Kross, E, Verduyn P, Demiralp, E, Park, J, Lee, D. S., Lin, N., et al. (2013) Facebook Use Predicts Declines in Subjective Well-Being in Young Adults. PLoS ONE, 8(8), e69841. doi:10.1371/journal.pone.0069841

Lenhart A. (2009) Teens and Sexting. Pew Research Center; Washington, DC. http://pewinternet.org/Reports/2009/ Teens-and-Sexting.aspx. Accessed May 25th 2016.

Liu, T., \& Potenza, M. N. (2007). Problematic Internet use: Clinical implications. CNS Spectrum, 12, 453-466. http://dx.doi.org/10.1017/S1092852900015339

Lu, X., Watanabe, J., Liu, Q., Uji, M., Shono, M., \& Kitamura, T. (2011). Internet and mobile phone text-messaging dependency: Factor structure and correlation with dysphoric mood among Japanese adults. Computers in Human Behavior, 27(5), 1702-1709. http://dx.doi.org/10.1016/j.chb.2011.02.009

Manago, A., Taylor, T., \& Greenfield, P. (2012). Me and my 400 friends: The anatomy of college students' Facebook networks, their communication patterns, and well-being. Developmental Psychology, 48, 369-380. http://dx.doi.org/10.1037/a0026338

Mehdizadeh, S. (2010). Self-presentation 2.0: Narcissism and self-esteem on Facebook. Cyberpsychology, Behavior, and Social Networking, 13(4), 357-364. http://dx.doi.org/10.1089/cyber.2009.0257.

Melillo, R. (2009). Disconnected Kids. New York: Penguin Group.

Mental Health Foundation (MHF). (2013). Starting Today: The Future of Mental health services. Final Enquiry Report.

Mitchell, P. (2000). Internet addiction: Genuine diagnosis or not? Lancet, 355. http://dx.doi.org/10.1016/S0140-6736(05)72500-9

O'Keeffe, G., \& Clarke-Pearson, K. (2011). Council on Communications and Media- Clinical Report- The Impact of Social Media on Children, Adolescents, and Families, American Academy of Pediatrics, 127, 800-804. http://dx.doi.org/10.1542/peds.2011-0054

Palfrey, J., Glasser, U., \& Boyd, D. (2010). Empowering Parents and Protecting Children in an Evolving Media Landscape. Cambridge, Massachusetts: Berkman Center for Internet and Society at Harvard University.

Palmer, S. (2006). Toxic Childhood. London: Orion Publishing.

Pea, R., Nass ,C., Meheula, L, Rance, M, Kumar, A., Bamford, H., Nass, M, Simha, A., Stillerman, B., Yang, S., \& Zhou, M. (2012). Media use, face-to-face communication, media multitasking, and social well-being among 8- to 12-year-old girls. Developmental Psychology, 48, 327-336. http://dx.doi.org/ 10.1037/a0027030 
Plowman, L., \& McPake, J. (2013) Seven Myths About Young Children and Technology. Childhood Education, 89(1) $27 \mathrm{~K} 33$.

Plowman, L., McPake, J., \& Stephen, C. (2010). The Technologisation of Childhood? Young Children and Technology in the home. Children and Society, 24, 63-74. http://dx.doi.org/10.1111/j.1099-0860.2008.00180.x

Reich, S., Subrahmanyam, K., \& Espinoza, G. (2012). Friending, IMing, and hanging out face-to-face: Overlap in adolescents' online and offline social networks. Developmental Psychology, 48, 356-368. http://dx.doi.org/10.1037/a0026980

Rheingold, H. (1993). The virtual community: Homesteading on the electronic frontier. Reading, MA: Addison Wesley.

Rosen, L. D., Whaling, K., Rab, S., Carrier, L. M., \& Cheever, N. A. (2013). Is Facebook Creating "iDisorders"? The Link Between Clinical Symptoms of Psychiatric Disorders and Technology Use, Attitudes and Anxiety. Computers in Human Behavior, 29, 1243-1254. http://dx.doi.org/10.1016/j.chb.2012.11.012

Ryan, T., \& Xenos, S. (2011). Who uses Facebook? An investigation into the relationship between the Big Five, shyness, narcissism, loneliness, and Facebook usage. Computers in Human Behavior, 27(5), 1658-1664. http://dx.doi.org/ 10.1016/j.chb.2011.02.004

Steinfield, C., Ellison, N., \& Lampe, C. (2008). Social capital, self-esteem, and use of online social network sites: A longitudinal analysis. Developmental Psychology, 29, 434-445. http://dx.doi.org/10.1016/j.appdev.2008.07.002

Stoll, C. (1995). Silicon snake oil: Second Thoughts on the Information Highway. New York: Doubleday.

Turkle, S. (1996). Virtuality and its discontents: Searching for community in cyberspace. The American Prospect, 24, 50-57.

United Nations Convention on the Rights of the Child (UNCRC). (1989). Your rights under the UNCRC- United Nations Children's Fund (UNICEF) Youth Voice: http://www.unicef.org/crc/ (Accessed 20/09/15-27/09/15).

Van Scoter, J., D. Ellis, \& J. Railsback (2001). Technology in Early Childhood Education: finding the balance. Northwest Regional Educational Laboratory, Portland, Oregon.

Young, K. S., \& Rodgers, R. C. (1998). The Relationship between depression and Internet addiction. Cyber Psychology \& Behavior, 1, 25-28. http://dx.doi.org/10.1089/cpb.1998.1.25

Young, M. (2001) Technology and Early Child Development. TechKnowLogia, 3, 13-14.

\section{(cc) $\mathrm{BY}$}

This work is licensed under a Creative Commons Attribution 3.0 License. 